The BMJ

Cite this as: $B M J 2021 ; 372: n 81$ http://dx.doi.org/10.1136/bmj.n81 Published: 12 January 2021

\section{Covid-19: Controversial rapid test policy divides doctors and scientists}

\section{Zosia Kmietowicz}

The UK government's new policy of distributing rapid coronavirus tests to local authorities in England has divided the medical and scientific community, with some calling for the tests to be halted because they could falsely reassure people and increase the spread of covid-19.

Critics are also concerned that the policy, announced on Sunday 10 January, was being rolled out without sufficient provision for people who test positive, such as putting them in hotels and compensating them financially. Supporters say the tests are a valuable additional tool in public health interventions to identify new cases and suppress further transmission.

Launching the new testing drive, England's health and social care secretary, Matt Hancock, said, "With roughly a third of people who have coronavirus not showing symptoms, targeted asymptomatic testing and subsequent isolation is highly effective in breaking chains of transmission. Rapid, regular testing is led by local authorities who design programmes based on their in-depth knowledge of the local populations, so testing can have the greatest impact."

As many as 131 local authorities have signed up to the initiative, and 107 have begun testing, Hancock said. Many areas, including Essex and Milton Keynes, were carrying out tests among critical workers and people who have to leave home for essential reasons. The government said that the tests, which provide results in 30 minutes, are accurate and reliable and have helped to identify more than 14800 covid-19 cases that would have gone unrecognised.

The move came after a U turn by the Medicines and Healthcare Products Regulatory Agency, which had initially deemed the Innova test not fit for use among asymptomatic people in the community but changed its guidance for this purpose on 23 December.

Plans to test communities for the virus were detailed in the government's Moonshot documents, revealed by The BMJ in September. ${ }^{2}$

Iain Buchan, executive dean and chair in public health and clinical informatics at the University of Liverpool, who led the analysis of a pilot of community testing in the city, ${ }^{4}$ said that the Innova test had become a valuable tool within a wider public health intervention that was popular with the public. The test had identified 8300 people in the area with SARS-CoV-2 infection, he added. "A third of Liverpool's population have now been tested, and repeat testing is becoming a way of life," he said. However, the pilot report said that there was no clear evidence yet that testing in Liverpool had had an effect on numbers of covid-19 cases or hospital admissions.
It said, "Targeting testing, and vaccination, to save the most lives and livelihoods possible over the coming months will require close working of local public health, NHS, academic and third sector organisations-looking daily at the same data [and] intelligence and adapting locally authentic communications quickly."

However, Buchan emphasised that the most deprived groups in society, who had the lowest testing uptake but the highest infection rates, needed further resources to ensure they received support to isolate.

\section{"Red light" tests}

Shaun Fitzgerald, director of the Centre for Climate Repair at the University of Cambridge, said, "The regular testing of students last term across Cambridge University really helped identify new cases. The resulting immediate isolation of households then enabled the transmission to be seriously suppressed. Early detection of emerging cases can have a significant impact, so having this rolled out country-wide is a positive step.”

Adam Finn, professor of paediatrics at the University of Bristol, was also supportive of the strategy. "These are 'red light' tests," he said. "If they come up positive that means you are potentially infectious to others and must self-isolate. They are not 'green light' tests: you cannot be sure that if the test is negative you are not infectious, and you must continue to take the usual precautions. Even though the vaccine programme is now ramping up, it will be some time before it has a major impact on the number of hospitalisations and deaths.”

Sheila Bird, formerly programme leader at the Medical Research Council's Biostatistics Unit in Cambridge, said that there was a merit to testing for SARS-CoV-2 in key workers, but that the messaging should not mislead.

"Uptake of repeated testing needs to be monitored and practical support given for key workers who test positive and are required to self-isolate," she said. "Their self-isolation should itself include random testing to glean intelligence on whether the period of self-isolation can be reduced or needs to lengthen-dependent on whether the key worker was (or was not) infected by the variant of concern. Early RT-PCR testing of other self-isolating members of an infected key worker's household, and repeat testing after (say) seven days, would allow more efficient learning about within-household transmission than test and trace (without follow-up testing) has delivered thus far."

Similarly, Christina Pagel, professor of operational research at University College Member and a member of the Independent Scientific and Advisory Group of Experts, said that regular repeated testing reduced 
the chances of a false negative result and could play an important role in reducing transmission among people who cannot work at home. But she said that those who tested positive needed financial and practical support to self-isolate. "Additionally, if people (wrongly) believe that a negative test means they are 'safe' and don't need to follow social distancing, or even go to work if they have symptoms, then mass testing could make things worse. Communication is crucial," she said.

However, many scientists are concerned that the tests are too inaccurate and will not help to contain the spread of the virus. In the Liverpool pilot, they said, the test missed infection in $60 \%$ of people, and most worryingly it missed $30 \%$ of those in people with very high viral loads, who are at the highest risk of spreading the virus to others. ${ }^{3}$

\section{False reassurance}

Writing in BMJ Opinion, Jon Deeks, who leads the Cochrane Collaboration's covid-19 test evaluation activities, Angela Raffle, a health screening expert from the University of Bristol, and Mike Gill, a former member of the UK National Screening Committee, said that the government was misleading the public about the performance of the Innova test. 4

"Results from government studies have been selectively reported and some have not been reported at all. Letters to schools and parents have wrongly stated that the Innova tests were 'as accurate in identifying a case as a PCR test."”

They added, "The UK government is widening the roll out of the Innova lateral flow test without supporting evidence, and we understand that this may soon extend to further home use. This may cause serious harm. We call on the government urgently to change course."

Correction: On 13 January 2021 we updated the quotation from BMJ Opinion.

1 Mahase E. Covid-19: UK regulator approves lateral flow test for home use despite accuracy concerns. BMJ 2020;371:m4950. doi: 10.1136/bmj.m4950 pmid: 33361088

2 lacobucci G, Coombes R. Covid-19: Government plans to spend $f 100 \mathrm{bn}$ on expanding testing to 10 million a day. BMJ2020;370:m3520. doi: 10.1136/bmj.m3520 pmid: 32907851

3 Liverpool covid-19 community testing pilot: interim evaluation report. Dec 2020.

https://www.liverpool.ac.uk/media/livacuk/coronavirus/Liverpool,Community,Testing,Pilot,Interim,Evaluation.pdf.

4 Deeks J, Raffle A, Gill M. Covid-19: government must urgently rethink lateral flow test roll out. BMJ Opinion. 12 Jan 2021. https://blogs.bmj.com/bmj/2021/01/12/covid-19-government-musturgently-rethink-lateral-flow-test-roll-out.

This article is made freely available for use in accordance with BMJ's website terms and conditions for the duration of the covid-19 pandemic or until otherwise determined by BMJ. You may use, download and print the article for any lawful, non-commercial purpose (including text and data mining) provided that all copyright notices and trade marks are retained. 